\title{
Prevention of H-Aggregates Formation in Cy5 Labeled Macromolecules
}

\author{
Jing Kang, ${ }^{1}$ Oliver Kaczmarek, ${ }^{2}$ Jürgen Liebscher, ${ }^{2}$ and Lars Dähne1 \\ ${ }^{1}$ Surflay Nanotec GmbH, Schwarzschildstr. 8, 12489 Berlin, Germany \\ ${ }^{2}$ Institute of Chemistry, Humboldt University, of Brook-Taylor-Str. 2, 12489 Berlin, Germany
}

Correspondence should be addressed to Lars Dähne, 1.daehne@surflay.com

Received 13 November 2009; Revised 23 February 2010; Accepted 14 March 2010

Academic Editor: Jinying Yuan

Copyright ( $) 2010$ Jing Kang et al. This is an open access article distributed under the Creative Commons Attribution License, which permits unrestricted use, distribution, and reproduction in any medium, provided the original work is properly cited.

\begin{abstract}
$\mathrm{H}$-aggregates of the cyanine dye Cy5 are formed during covalent linkage to the cationic macromolecule Poly(allylamine) (PAH). The nonfluorescent $\mathrm{H}$-aggregates strongly restrict the usage of the dye for analytical purposes and prevent a quantitative determination of the labeled macromolecules. The behavior of the H-aggregates has been studied by investigation of the absorption and fluorescence spectra of the dye polymer in dependence on solvent, label degree and additional sulfonate groups. $\mathrm{H}$-aggregate formation is caused by an inhomogeneous distribution of the Cy5 molecules on the polymer chain. The $\mathrm{H}$-aggregates can be destroyed by conformational changes of the PAH induced by interactions with polyanions or in organic solvents. It has been found that the polymer labeling process in high content of organic solvents can prevent the formation of $\mathrm{H}$-aggregates. The results offer a better understanding and improvement of the use of the Cy5 dye for labeling purposes in fluorescence detection of macromolecules.
\end{abstract}

\section{Introduction}

The labeling of biological or technical materials with fluorescent dyes has gained a great importance in connection with the development of new modern fluorescencebased analytical techniques such as Fluorescence Correlation Spectroscopy (FCS) [1, 2], Single Molecule Spectroscopy (SMS) [3], Confocal Laser Scanning Microscopy (CLSM) [4], Fluorescence Resonance Energy Transfer (FRET) [5], Fluorescence Recovery after Photobleaching (FRAP) [6], or time resolved spectroscopic methods down to femtoseconds $[7,8]$. For all of these processes the spectroscopic parameters of the dye molecules such as excitation and emission spectra, lifetime and fluorescence quantum yield are important but often change in an unpredictable way by the labeling procedure [9-12]. Especially in the case of proteins high label degrees or label sites in close neighborhood lead to a strong decrease of the fluorescence quantum yield as well as a shift of absorption and fluorescence energy [13-15].
We investigated these processes on the well-known chromophore Bis(indolenyl)pentamethincyanine that is commercially available under the label name Cy5 (Figure 1). Strong changes in the spectroscopic properties of the dye have been observed earlier by simple adsorption of the positively charged chromophore to negatively charged macromolecules, namely, polyanions $[16,17]$. In this paper we studied the spectroscopic behavior of the dye after covalent linkage to the cationic macromolecule PAH. The polyelectrolyte $\mathrm{PAH}$ of molecular weight $70 \mathrm{kDa}$ can not only serve as a simple model for proteins below their isoelectric point (IEP) but also it is an important material used in Layer-by-Layer technology allowing the formation of multilayers of alternatively charged polyelectrolytes on planar and colloidal substrates $[18,19]$.

Formation of $\mathrm{Cy} 5 \mathrm{H}$-aggregates was observed after the labeling procedure. Such non-fluorescent $\mathrm{H}$-aggregates remarkably restrict the applicability of fluorescent dyes in analytical methods. Therefore, efforts have been made to investigate the factors that could reduce $\mathrm{H}$-aggregates 


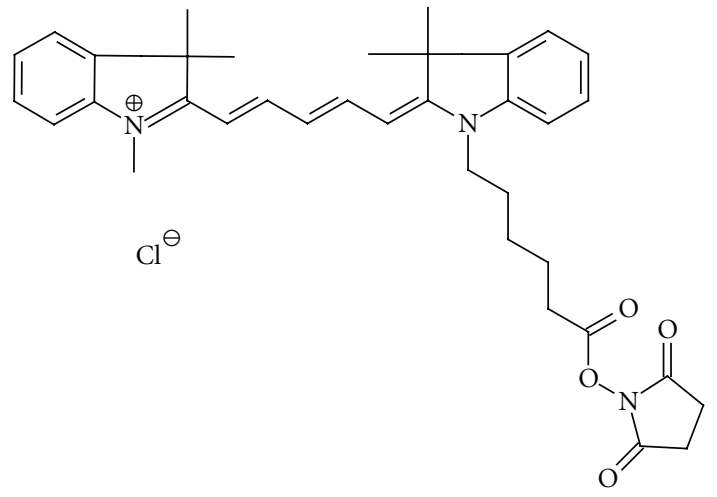

(a) $\mathrm{Cy} 5$

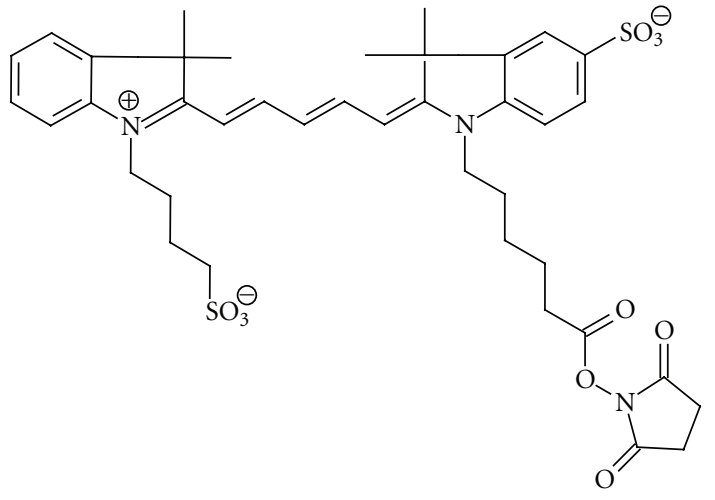

(b) Sulfo-Cy5 (Cy5 with two additional sulfonate groups)

FIGURE 1: Chromophore structures of Bis(indolenyl)pentamethincyanine.

formation such as solvent, ion strength and complexation with oppositely charged polymers in order to improve the cyanine dye labeling process.

\section{Experimental Part}

2.1. Materials. PAH ( $\mathrm{Mw}$ 70.000), poly(styrenesulfonate) (PSS, Mw 70.000), dimethylformamide (DMF), methanol, acetone, dimethyl sulfoxide (DMSO) and buffer materials were purchased from Aldrich (Germany); poly(methacrylic acid) (PMAA, Mw 100.000) was purchased from PolyScience Inc. (USA). All chemicals were in high purity (spectroscopic grade) and were used as received. The Sulfo-Cy5 was received from FEW Wolfen (Germany) for research purposes.

2.2. Absorption and Fluorescence Masurements. Absorption spectroscopy was obtained using a Varian Cary $50 \mathrm{UV} / \mathrm{Vis}$ spectrophotometer. The fluorescence spectra were taken using a Varian Cary Eclipse. Spectra were taken with samples in quartz cuvettes of $1 \mathrm{~cm}$ in thickness.

2.3. Preparation of Cy5 (2-(3-\{1-[5-(2,5-Dioxopyrrolidin-1Yloxycarbonyl)-Pentyl]-3,3-Dimethyl-1,3-Dihydro-Indol-2Ylidene\}-Propenyl-1,3,3-Trimethyl-3H-Indolium Tetrafluoroborate). The corresponding Cy5-carboxylic acid Tetrafluoroborate $(756 \mathrm{mg}, 1.38 \mathrm{mmol}$ ) was dissolved in dry dichloromethane $(25 \mathrm{~mL})$ and stirred under argon. Ethyl- diisopropylamine $\left(258 \mathrm{mg}, 2.77 \mathrm{mmol}\right.$ ) and $\mathrm{N}, \mathrm{N}^{\prime}$-disuccinylcarbonate $(392 \mathrm{mg}, 1.53 \mathrm{mmol}$ ) were added under argon. The mixture was stirred at room temperature for 20 hours, then diluted with dichloromethane $(20 \mathrm{~mL})$ and washed successively with water, $32 \%$ aqueous Tetrafluoroboronic acid and water. The organic layer was separated, dried $\left(\mathrm{Na}_{2} \mathrm{SO}_{4}\right)$ and concentrated. The remainder was stirred in diethylether $(40 \mathrm{~mL})$. The ethereal phase was separated and the ether stripped off to give the product ( $780 \mathrm{mg}, 88 \%$ yield).

NMR Analysis of This Synthesized Compound. ${ }^{1} \mathrm{H}-\mathrm{NMR}$ $\left(\mathrm{CDCl}_{3}\right) \delta(\mathrm{ppm}): 1.50\left(\mathrm{~m}, 2 \mathrm{H}, 2 \mathrm{CH}_{2}\right), 1.59\left(\mathrm{~s}, 12 \mathrm{H}, 4 \mathrm{CH}_{3}\right)$, $1.70\left(\mathrm{~m}, 4 \mathrm{H}, 2 \mathrm{CH}_{2}\right), 2.49\left(\mathrm{t}, 2 \mathrm{H}, \mathrm{CH}_{2} \mathrm{COO}\right), 2.69(\mathrm{~s}, 4 \mathrm{H}$,
$\mathrm{COCH}_{2} \mathrm{CH}_{2} \mathrm{CO}$ ), 3.55 (s, $\left.3 \mathrm{H}, \mathrm{NCH}_{3}\right), 3.98\left(\mathrm{t}, 2 \mathrm{H}, \mathrm{NCH}_{2}\right.$ ), $6.46(\mathrm{t}, 2 \mathrm{H}, 2 \mathrm{CH}=), 7.04(\mathrm{t}, 2 \mathrm{H}$, aryl $), 7.12(\mathrm{t}, 2 \mathrm{H}$, aryl $)$, $7.26(\mathrm{~m}, 4 \mathrm{H}$, aryl $), 8.29(\mathrm{t}, 1 \mathrm{H}, \mathrm{CH}=) .{ }^{13} \mathrm{C}-\mathrm{NMR}\left(\mathrm{CDCl}_{3}\right)$ $\delta(\mathrm{ppm}): 24.7\left(\mathrm{CH}_{2}\right), 25.3\left(\mathrm{CH}_{2}\right), 25.4\left(\mathrm{CH}_{2}\right), 26.7\left(\mathrm{CH}_{2}\right)$, $27.8\left(\mathrm{CH}_{3}\right), 27.9\left(\mathrm{CH}_{3}\right), 30.4\left(\mathrm{CH}_{2}\right), 31.3\left(\mathrm{CH}_{3}\right), 44.0\left(\mathrm{CH}_{2}\right)$, $48.9(\mathrm{C}), 49.0(\mathrm{C}), 103.3(\mathrm{CH}), 103.8(\mathrm{CH}), 110.8(\mathrm{CH})$, $122.0(\mathrm{CH}), 122.1(\mathrm{CH}), 125.3(\mathrm{CH}), 125.4(\mathrm{CH}), 128.7$ $(\mathrm{CH}), 128.8(\mathrm{CH}), 140.3(\mathrm{C}), 140.4(\mathrm{C}), 141.7(\mathrm{C}), 142.4(\mathrm{C})$, 150.6(CH), 168.5(C), 169.3(C), 173,8(C), 174.5(C).

\section{Mass Spectrometry.}

Calculated for $\mathrm{C}_{36} \mathrm{H}_{42} \mathrm{~N}_{3} \mathrm{O}_{4}: 580.3175 \mathrm{~g} / \mathrm{mol}$

Determined: $580.3210 \mathrm{~g} / \mathrm{mol}$ for Mol Peak

UV/Vis Spectroscopy.

$$
\begin{aligned}
& \text { Literature [20]: } \varepsilon_{640 \mathrm{~nm}}(\mathrm{MetOH}) \\
& =250000 \mathrm{lmol} \mathrm{mom}^{-1} \\
& \text { Determined: } \varepsilon_{640 \mathrm{~nm}}(\mathrm{MetOH})=256700 \mathrm{lmol}^{-1} \mathrm{~cm}^{-1} \\
& \text { Determined: } \varepsilon_{640 \mathrm{~nm}}\left(\mathrm{H}_{2} \mathrm{O}\right)=2304001 \mathrm{~mol}^{-1} \mathrm{~cm}^{-1}
\end{aligned}
$$

2.4. Preparation of $P A H-C y 5$. PAH was dissolved in borate buffer $(50 \mathrm{mM}, \mathrm{pH} 8.0)$ to a final concentration of $1.0 \mathrm{~mol} / \mathrm{L}$ and Cy5 (or Sulfo-Cy5) was dissolved in DMF to a final concentration of $0.1 \mathrm{~mol} / \mathrm{l}$. A solvent mixture consisting of $75 \%$ borate buffer and 25\% DMF was used to synthesize $\mathrm{PAH}-\mathrm{Cy} 5 \mathrm{~A}$ and PAH-Cy5 C (when Sulfo-Cy5 is in use). A mixture of $25 \%$ borate buffer and $75 \%$ DMF was used to synthesize PAH-Cy5 B. Molar ratio between monomer unit of the polymer and dye molecules was controlled for producing PAH-Cy5 with different label degrees. The reaction was performed under stirring at room temperature overnight ( 24 hours). The product was dialyzed with membrane of Mwco $<15,000$ for one week against deionized water and thereafter filtered and lyophilized. The label degree of dye molecules on the polymer chain was determined by UV spectroscopy in $10 \mathrm{mM}$ Tris buffer, $\mathrm{pH}$ 7.0. The extinction coefficient for $\mathrm{Cy} 5, \varepsilon_{\mathrm{Cy} 5}$ was determined and taken as $230.400 \mathrm{M}^{-1} \mathrm{~cm}^{-1}$ at $640 \mathrm{~nm}$, while $\varepsilon_{\mathrm{Cy} 5}$ for Sulfo-Cy5 
is $187.000 \mathrm{M}^{-1} \mathrm{~cm}^{-1}$ (FEW Wolfen) at $645 \mathrm{~nm}$ in water. For calculation of the label degree, only the absorption maximum at $640 \mathrm{~nm}$ and $645 \mathrm{~nm}$ (for Sulfo-Cy5) has been used, respectively.

\section{Results and Discussion}

The absorption spectrum of the dye labeled polymer PAHCy $5 \mathrm{~A}$ is remarkably different to the spectrum of the free dye Cy5 (Figure 2).

A new absorption band appears at $590 \mathrm{~nm}$ close to the vibrational transition of the dye at $602 \mathrm{~nm}$. In contrast, the fluorescence spectra of the free dye and the polymer bound dye have the same shape and peak wavelength (Figure 2), although the free dye has a $14.8 \%$ higher fluorescence intensity. These experimental results can have two different origins: either a new species is formed by the labeling procedure or the vibrational structure of the dye has changed, which is well known for certain dyes such as for example, pyrene [21]. In order to distinguish between these possibilities the fluorescence excitation spectra have been measured for the free and the immobilized dye (Figure 3). They are identical but do not show the peak at $590 \mathrm{~nm}$. Hence the UV/Vis spectrum of the PAH-Cy5 shows the superposition of the single Cy5 molecule and another nonefluorescent species.

The spectrum of the new species is estimated by the difference of the spectra of labeled polymer and the free dye. The $14.8 \%$ lower fluorescence intensity of PAH-Cy5 compared to that of the free dye reveals the percentage of spectrum contribution of the new non-fluorescent species in $\mathrm{PAH}-\mathrm{Cy} 5$ at the maximum at $640 \mathrm{~nm}$. Taken this into account, the absorption spectrum of the new species is estimated. Its spectrum has an absorption maximum at $588 \mathrm{~nm}$ and a broad shoulder around $645 \mathrm{~nm}$. Such hypsochromic shift of absorption to higher energy could have its origin in the formation of dye $\mathrm{H}$-aggregates or dimers [22]. Formation of pure $\mathrm{H}$-aggregate from the Cy5 dye has been observed earlier when it was adsorbed to PSS (Cy5/PSS) in a $1: 1$ dye to monomer ratio $[16,17]$. However, the spectrum of Cy5-H-aggregate on PSS (Cy5/PSS) has a quite different shape compared to that of $\mathrm{PAH}-\mathrm{Cy} 5$ (Figure 3 ) pointing to a different arrangement and orientation of the dye molecules to each other. The maximum is at $556 \mathrm{~nm}$ and the shoulder around $645 \mathrm{~nm}$ is less pronounced as negligible.

The formation of $\mathrm{H}$-aggregates and the observed differences can be explained in terms of the Kasha-theory and the Davydov splitting (Scheme 1) [22-24]. The hypsochromic absorption shift is caused by transition dipole interactions between two or more chromophores arranged parallel to each other (H-aggregates) with a large slip angle $\alpha[23,24]$. The interaction of two transition dipoles M1 and M2 yield an energetic splitting of the excited state in two components $\mathrm{m}_{+}$and $\mathrm{m}_{-}$. In the case of parallel alignment of dye molecules, the absorption and emission from one energy level is forbidden because the resulting transition moment $\mathrm{m}_{-}=\mathrm{M} 1-\mathrm{M} 2=0$. Only the state $\mathrm{m}_{+}=\mathrm{M} 1+\mathrm{M} 2$ can be populated. In $\mathrm{H}$-aggregates, the allowed $\mathrm{m}_{+}$state has a

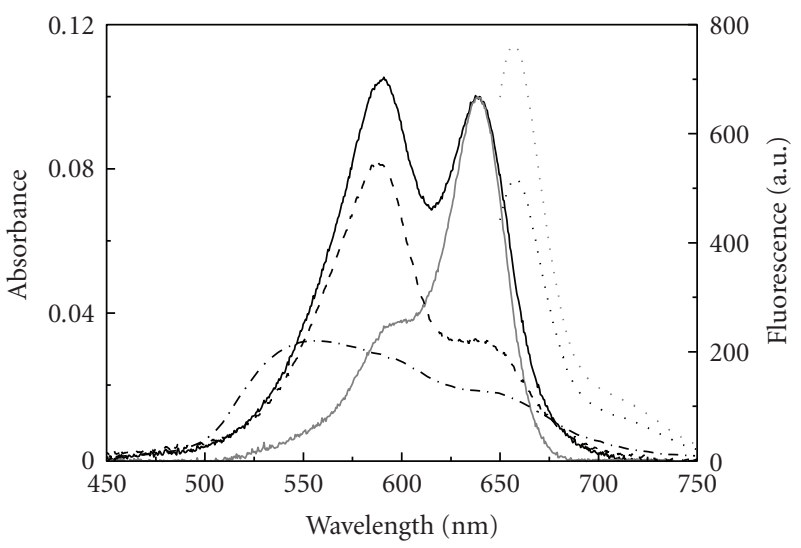

FIGURE 2: Absorption (solid lines) and fluorescence spectra (dotted lines) of PAH-Cy5 A (black) and Cy5 (grey). The fluorescence spectra were taken for excitation in the maximum $\lambda_{\mathrm{ex}}=638 \mathrm{~nm}$. The absorption spectrum of the new species is calculated (dashed line). For comparison, the $\mathrm{H}$-aggregate spectrum of Cy5/PSS is given (dash-dotted line) $[16,17]$.

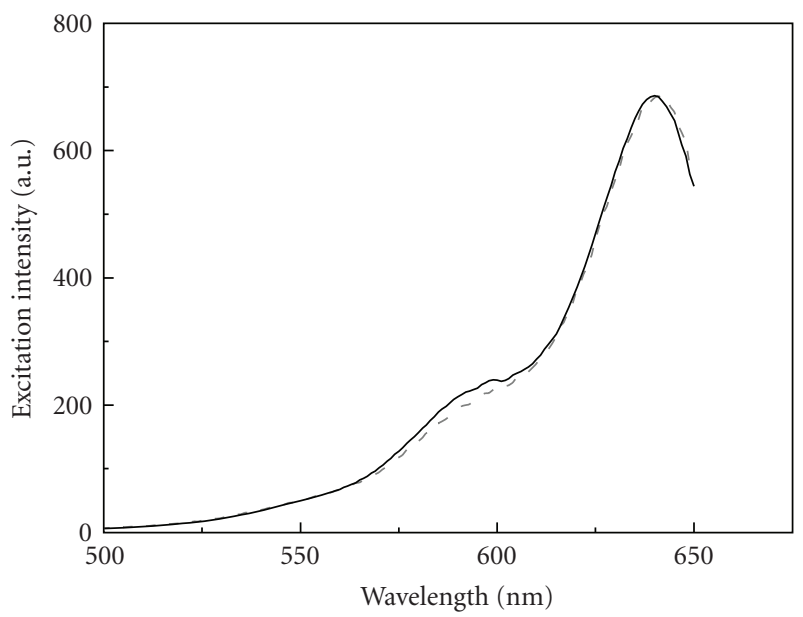

Figure 3: Excitation spectra of Cy5 (black lines) and PAH-Cy5 A (dashed grey line).

higher energy than the $\mathrm{m}_{-}$state and the monomer. This leads to the observed hypsochromic shift of the absorption energy with respect to the monomer. In this case the $\mathrm{m}_{+}$state shows no fluorescence due to fast internal conversion process to the nonemitting $\mathrm{m}_{-}$state, in which the radiative decay is forbidden. In agreement with that, the $\mathrm{Cy} 5 \mathrm{H}$-aggregates show no fluorescence.

The two absorptions found for the PAH-Cy5 could be caused by a slightly inclined orientation of dye molecules to each other like in a herringbone aggregate. Then, both transitions become allowed and can be observed as Davydov components at different wavelength. The intensity ratio between the peaks depends on the angle between the molecule axes (transition dipoles). This could cause the observed shoulder at $642 \mathrm{~nm}$.

The difference of the Cy5/PSS to the PAH-Cy5 spectrum can be explained by the high $1: 1$ ratio of dye molecules to 

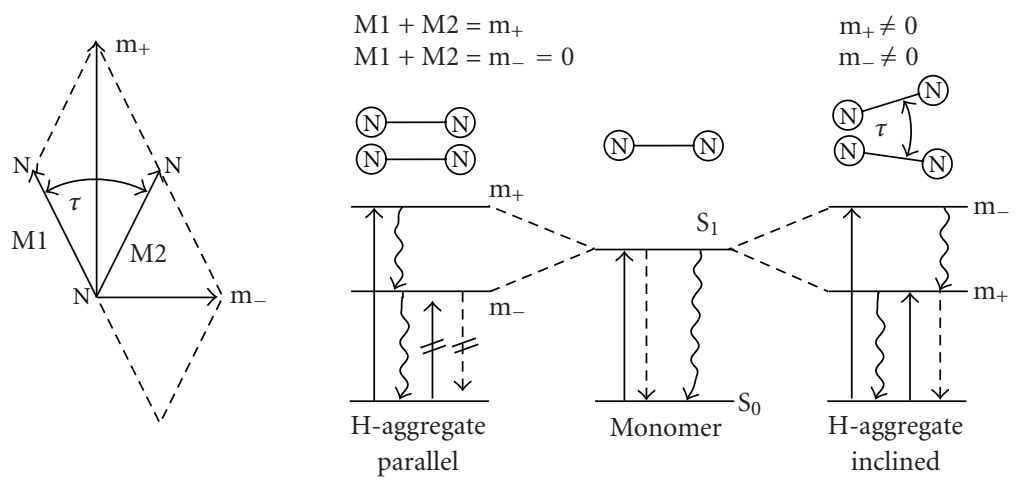

$\tau$ : angle between $\mathrm{M} 1$ and $\mathrm{M} 2$

M1, M2: molecular transition dipoles

$\mathrm{m}_{+}, \mathrm{m}_{-}$: resulting Davydov components

Scheme 1: Left: scheme of Davydov splitting; Right: model of molecule orientation and transition dipole interactions in dye H-aggregates and their absorption and fluorescence properties. The dumbbells model the dye molecules, solid arrows mark the absorption, broken arrows the fluorescence and wavy arrows the internal conversion, crossed lines are forbidden transitions.

(1)

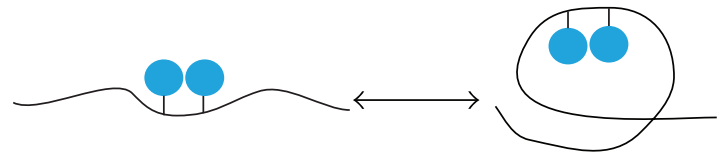

(2)

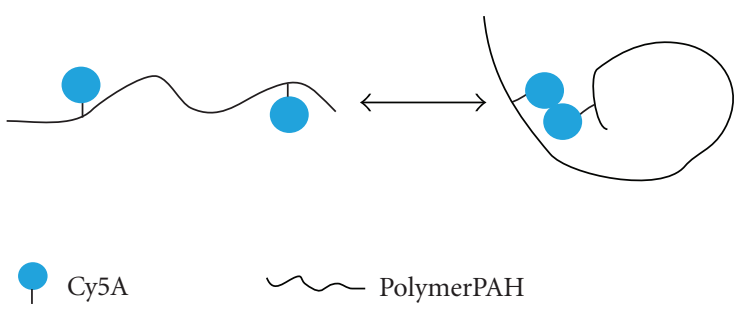

Scheme 2: Two possible ways of dye aggregates formation on PAHCy5.

monomer units on the polymer in Cy5/PSS and by the less spatial constraints compared to the covalently linked PAHCy5. The concentration of the dye molecules adsorbed on PSS is more than 600 times higher, yielding almost complete vanishing of the monomer absorption and the fluorescence. The dye molecules are obviously all in parallel alignment that is, the long wavelength absorption is not present. In contrast, the large constraints of Cy5 in PAH-Cy5 and the lower dye concentration result in a relatively high content of nonaggregated dye molecules. The aggregates consists of inclined molecules, producing the shoulder around $645 \mathrm{~nm}$ as second Davydov-component [22].

In order to eliminate the $\mathrm{H}$-aggregates on the polymer, PAH-Cy5 A with lower label degrees have been synthesized (Figure 4). The aggregate band becomes smaller with decreasing label degree, which proves less dye interactions and aggregate formation. However, even at low label degree of $1: 1500$, theoretically with less than half a dye molecule bound to one polymer molecule, aggregates still exist. Hence,

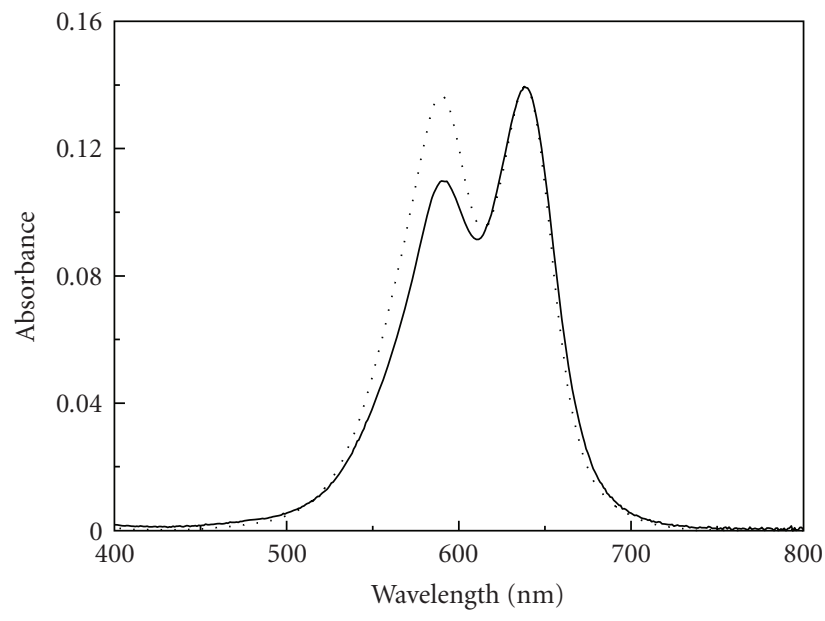

FIgure 4: Absorption spectra of PAH-Cy5 A with dye label degree of $1: 1500$ (solid line) and $1: 840$ (dotted line).

the formation of $\mathrm{H}$-aggregate on the chain can have two possible reasons (Scheme 2):

(1) The dye molecules are not statistically distributed along the PAH chain. This could be due to a preferred attachment of the dyes in direct neighborhood on the PAH chains during the reaction.

(2) The dye molecules are statistically evenly distributed but due to well-known tangling of polyelectrolyte in aqueous solution, even dye molecules located far from each other could form aggregates.

The tangling level of polyelectrolyte depends highly on the ion strength of the surrounding aqueous solution due to shielding of the charges $[25,26]$. In pure water, the polymer chain is stretched, which should bring statistically distributed dye molecules far away from each other. We investigated 


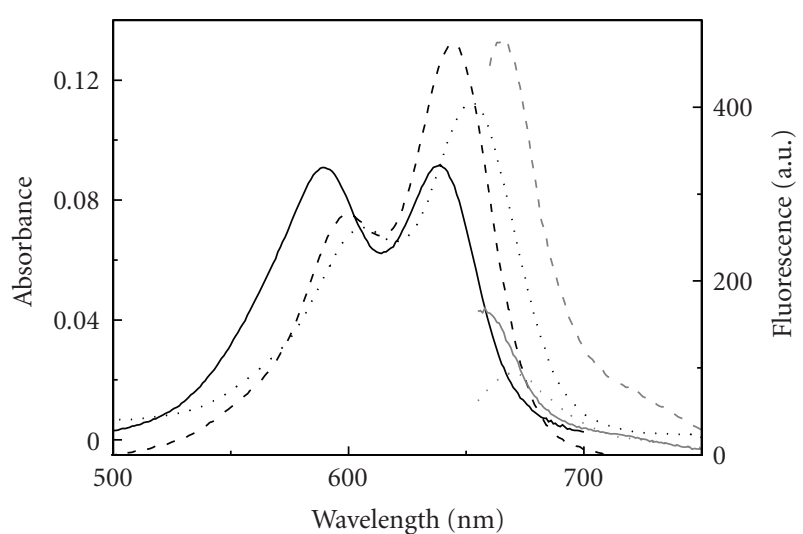

FIGURE 5: Absorption (black lines) and fluorescence spectra (grey lines) of PAH-Cy5 A ( $1: 840)$ in various solvent: DMF (dashed line), $\mathrm{H}_{2} \mathrm{O}$ (solid line) and PSS solution (CPSS $=5 \mathrm{mg} / \mathrm{mL}$ ) (dotted line). (Monomer ratio between PAH and PSS is $1: 12$.) The fluorescence spectra are taken with $\lambda_{\mathrm{ex}}=638 \mathrm{~nm}$ and a slit width of $5 / 10 \mathrm{~nm}$.

the absorption spectrum of the PAH-Cy5 solution in dependence on $\mathrm{NaCl}$ concentration in the range 0 and $0.25 \mathrm{M}$ (data not shown). The negligible changes in the absorption spectra exclude reason 2 and reveal reason 1: the Cy5 molecules are bound in very close neighborhood on the PAH chain and cause formation of $\mathrm{H}$-aggregates.

It is well known that dye aggregates can be dissolved by addition of organic solvents [27]. Furthermore, complexation of the PAH-Cy5 with a polycation can strongly change the conformation of the polymer and possibly destruct the aggregates. The interaction of PAH-Cy5 with PSS yielded a strong decrease of the band at $588 \mathrm{~nm}$, showing the disappearance of the $\mathrm{H}$-aggregate (Figure 5). Nevertheless, the fluorescence intensity decreased, probably due to the formation of polyelectrolyte complexes and an increase of dye density to the range where self-quenching exists. Furthermore, a bathochromic shift of absorption energy of the monomer dye molecules is observed, caused by the negative charge of the surrounding molecules (Table 1). This effect is also visible for the introduction of the sulfonate groups on the chromophor and it is not related to the aggregation phenomena.

Addition of $75 \%$ of organic solvents to the aqueous PAH-Cy5 A solution yielded an increase of the absorption in the monomer dye range at the cost of the $\mathrm{H}$-aggregate band. Simultaneously, the fluorescence intensity increased by almost three times. These findings prove the inhomogeneous distribution of the dye molecules in the PAH chain.

In order to minimize the formation of $\mathrm{H}$-aggregates on the PAH chain, we tried to reduce the interactions between the Cy5 molecules during the labeling reaction by the addition of different organic solvents, like methanol, acetone, DMSO and DMF. DMF has been identified as the optimal solvent for the labeling process. By such synthesis $\mathrm{PAH}-\mathrm{Cy} 5 \mathrm{~B}$ was prepared that showed remarkable less $\mathrm{H}$-aggregates. Also this dye has been used for labelling PAH in aqueous solution yielding PAH-Cy5 C. As shown absorbance and fluorescence
TABLE 1: Shift of absorption maxima $\lambda_{\mathrm{abs}}$ (in $\mathrm{nm}$ ) of Cy5 monomer band in different media.

\begin{tabular}{lccc}
\hline & Monomer $\lambda_{\text {abs }}$ & $\begin{array}{c}\text { Monomer } \lambda_{\text {abs }} \\
\text { in DMF }\end{array}$ & $\begin{array}{c}\text { Monomer } \lambda_{\text {abs }} \\
\text { in PSS solution }\end{array}$ \\
\hline Cy5 & 638 & 644 & 648 \\
PAH-Cy5 & 638 & 644 & 652 \\
PAH- & 644 & 650 & 655 \\
(SulfoCy5) & 644 & & \\
\hline
\end{tabular}

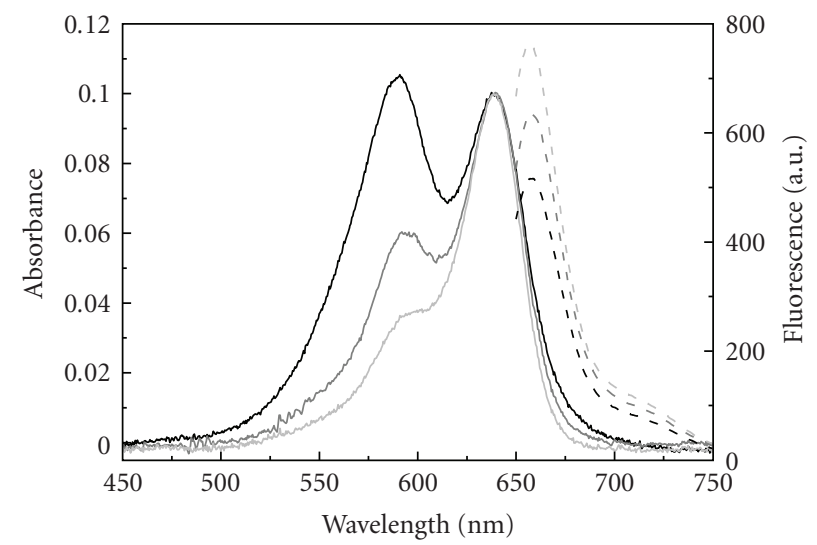

FIGURE 6: Absorption (solid lines) and fluorescence spectra (dashed lines) of PAH-Cy5 A (black), PAH-Cy5 B (grey) and Cy5 free dye (light grey) measured in aqueous solution. The concentration of the solutions is set to the absorption maximum. The fluorescence spectra are taken with $\lambda_{\mathrm{ex}}=638 \mathrm{~nm}$ and a slit width of $5 / 5 \mathrm{~nm}$.

spectra measured in aqueous solution show that the $\mathrm{H}$ aggregate peak of $\mathrm{PAH}-\mathrm{Cy} 5 \mathrm{~B}$ is much smaller compared to that of $\mathrm{PAH}-\mathrm{Cy} 5 \mathrm{~A}$, and the fluorescence quantum yield is significantly improved (Figure 6). However, the fluorescence quantum yield of free dye is still higher compared to the immobilized ones in PAH-Cy5 B.

For labeling of biological molecules the commercially available Cy5 chromophore is functionalized with two additional sulfonate groups increasing the solubility in water (Sulfo-Cy5, Figure 1). Hence, hydrophobic interactions supporting the formation of dye aggregates are less pronounced. This dye has been taken for the labeling procedure in aqueous solution. As shown in Figure 7, formation of $\mathrm{H}$ aggregates is less pronounced compared to the Cy5 without sulfonate groups, but they were still present and the content increased with the label degree. Hence, our findings are also valid for better understanding of the spectroscopic properties and usage of the more hydrophilic, sulfonated Cy5 chromophores.

\section{Conclusions}

In this paper, $\mathrm{H}$-aggregates of cyanine dye $\mathrm{Cy} 5$ covalently linked to the polymer PAH have been observed and the behavior of the "H-aggregate band" at different solvent and synthesis conditions has been investigated. In the PAHCy5 $\mathrm{H}$-aggregates, the absorption wavelength is shifted from 


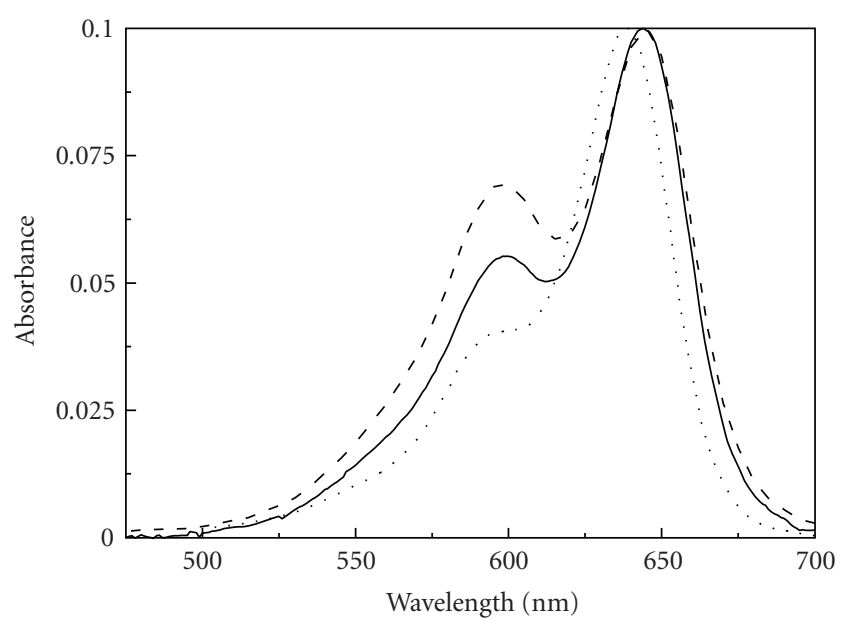

Figure 7: Absorption spectra measured from PAH-Cy5 C with label degrees 1:490 (solid line), $1: 320$ (dashed line), and the free dye Cy5 (dotted line).

$638 \mathrm{~nm}$ to $588 \mathrm{~nm}$. The H-aggregates show no fluorescence, which remarkably reduces the sensitivity and applicability of the dye labeled materials for analytical methods. The behavior of the coupled dye can be described well by the KASHA-theory and the Davydov-splitting. It was found that $\mathrm{H}$-aggregates were formed during the synthesis by interactions between dye molecules, leading to an inhomogeneous distribution along the polymer chain even at low label concentrations. In order to reduce this undesired effect a different synthetic route in $75 \%$ organic solvent has been developed yielding much higher label degrees and remarkable less $\mathrm{H}$-aggregates on the polymer. These findings open the door for better and wider use of Cy5 dyes in sensing and fluorescence detection applications.

\section{Acknowledgments}

This work was supported by a grant of the Federal Ministry of Education and Research (BMBF Project INUNA FKZ 0312027A).

\section{References}

[1] D. Pristinski, V. Kozlovskaya, and S. A. Sukhishvili, "Fluorescence correlation spectroscopy studies of diffusion of a weak polyelectrolyte in aqueous solutions," Journal of Chemical Physics, vol. 122, no. 1, article 014907, pp. 1-9, 2005.

[2] C. Reznik, Q. Darugar, A. Wheat, T. Fulghum, R. C. Advincula, and C. F. Landes, "Single ion diffusive transport within a poly(styrene sulfonate) polymer brush matrix probed by fluorescence correlation spectroscopy," Journal of Physical Chemistry B, vol. 112, no. 35, pp. 10890-10897, 2008.

[3] K. Becker and J. M. Lupton, "Efficient light harvesting in dyeendcapped conjugated polymers probed by single molecule spectroscopy," Journal of the American Chemical Society, vol. 128, no. 19, pp. 6468-6479, 2006.

[4] A. P. R. Johnston, A. N. Zelikin, L. Lee, and F. Caruso, "Approaches to quantifying and visualizing polyelectrolyte multilayer film formation on particles," Analytical Chemistry, vol. 78, no. 16, pp. 5913-5919, 2006.

[5] C.-Y. Zhang, H.-C. Yeh, M. T. Kuroki, and T.-H. Wang, "Single-quantum-dot-based DNA nanosensor," Nature Materials, vol. 4, no. 11, pp. 826-831, 2005.

[6] V. E. Keuren and W. Schrof, "Fluorescence recovery after twophoton bleaching for the study of dye diffusion in polymer systems," Macromolecules, vol. 36, no. 13, pp. 5002-5007, 2003.

[7] K. Ray, H. Nakahara, A. Sakamoto, and M. Tasumi, "Excitation energy transfer from symmetric cyanine dyes to unsymmetric merocyanine aggregated in functionalized Langmuir-Blodgett films by time-resolved fluorescence spectroscopy," Chemical Physics Letters, vol. 342, no. 1-2, pp. 58-64, 2001.

[8] K. Becker, J. M. Lupton, J. Feldmann, et al., "On-chain fluorenone defect emission from single polyfluorene molecules in the absence of intermolecular interactions," Advanced Functional Materials, vol. 16, no. 3, pp. 364-370, 2006.

[9] E. E. Jelly, "Spectral absorption and fluorescence of dyes in the molecular state," Nature, vol. 138, p. 1009, 1936.

[10] G. Scheibe, "Uber die veranderlichkeit der absorptionsspektren in losungen und die nebenvalenzen als ihre ursache," Angewandte Chemie, vol. 49, no. 31, p. 563, 1936.

[11] W. West, S. P. Lovell, and W. Cooper, "Electronic spectra of cyanine dyes at low temperature. 1," Photographic Science and Engineering, vol. 14, no. 1, pp. 52-62, 1970.

[12] U. Roesch, S. Yao, R. Wortmann, and F. Wuerthner, "Fluorescent H-aggregates of merocyanine dyes," Angewandte Chemie - International Edition, vol. 45, no. 42, pp. 7026-7030, 2006.

[13] R. W. Chambers, T. Kajiwara, and D. R. Kearns, "Effect of dimer formation of the electronic absorption and emission spectra of ionic dyes. Rhodamines and other common dyes," Journal of Physical Chemistry, vol. 78, no. 4, pp. 380-387, 1974.

[14] M. Van Der Auweraer, G. Biesmans, and F.-C. De Schryver, "On the photophysical properties of aggregates of 3-(2phenyl)-indolocarbocyanines," Chemical Physics, vol. 119, no. 2-3, pp. 355-375, 1988.

[15] H. J. Gruber, C. D. Hahn, G. Kada, et al., "Anomalous fluorescence enhancement of $\mathrm{Cy} 3$ and $\mathrm{Cy} 3.5$ versus anomalous fluorescence loss of Cy5 and Cy7 upon covalent linking to IgG and noncovalent binding to avidin," Bioconjugate Chemistry, vol. 11, no. 5, pp. 696-704, 2000.

[16] C. S. Peyratout, E. Donath, and L. Daehne, "Electrostatic interactions of cationic dyes with negatively charged polyelectrolytes in aqueous solution," Journal of Photochemistry and Photobiology A, vol. 142, no. 1, pp. 51-57, 2001.

[17] C. S. Peyratout, E. Donath, and L. Daehne, "Aggregation of thiacyanine derivatives on polyelectrolytes," Physical Chemistry Chemical Physics, vol. 4, no. 13, pp. 3032-3039, 2002.

[18] G. Decher, "Fuzzy nanoassemblies: toward layered polymeric multicomposites," Science, vol. 277, no. 5330, pp. 1232-1237, 1997.

[19] C. S. Peyratout and L. Daehne, "Tailor-Made Polyelectrolyte Microcapsules: From Multilayers to Smart Containers," Angewandte Chemie-International Edition, vol. 116, no. 29, pp. 3762-3783, 2004.

[20] R. B. Mujumdar, L. A. Ernst, S. R. Mujumdar, C. J. Lewis, and A. S. Waggoner, "Cyanine dye labeling reagents: sulfoindocyanine succinimidyl esters," Bioconjugate Chemistry, vol. 4, no. 2, pp. 105-111, 1993.

[21] F. M. Winnik, "Photophysics of preassociated pyrenes in aqueous polymer solutions and in other organized media," Chemical Reviews, vol. 93, no. 2, pp. 587-614, 1993. 
[22] A. S. Davydov, Theory of Molecular Excitons, McGraw-Hill, New York, NY, USA, 1962.

[23] M. Kasha, H. R. Rawls, and M. A. El-Bayoumi, "The exciton model in molecular spectroscopy," Pure and Applied Chemistry, vol. 11, pp. 371-392, 1965.

[24] D. Moebius, "Scheibe-aggregates: highly ordered systems of strongly interacting chromophores," Advanced Materials, vol. 7, pp. 437-444, 1995.

[25] A. Fery, B. Scholer, and T. Cassagneau, "Nanoporous thin films formed by salt-induced structural changes in multilayers of poly(acrylic acid) and poly(allylamine)," Langmuir, vol. 17, no. 3-4, pp. 3779-3783, 2001.

[26] R. Georgieva, R. Dimova, and G. Sukhorukov, "Influence of different salts on micro-sized polyelectrolyte hollow capsules," Journal of Materials Chemistry, vol. 15, no. 40, pp. 4301-4310, 2005.

[27] A. Mishra, G. B. Behera, M. M. G. Krishna, and N. Periasamy, "Time-resolved fluorescence studies of aminostyryl pyridinium dyes in organic solvents and surfactant solutions," Journal of Luminescence, vol. 92, no. 3, pp. 175-188, 2001. 

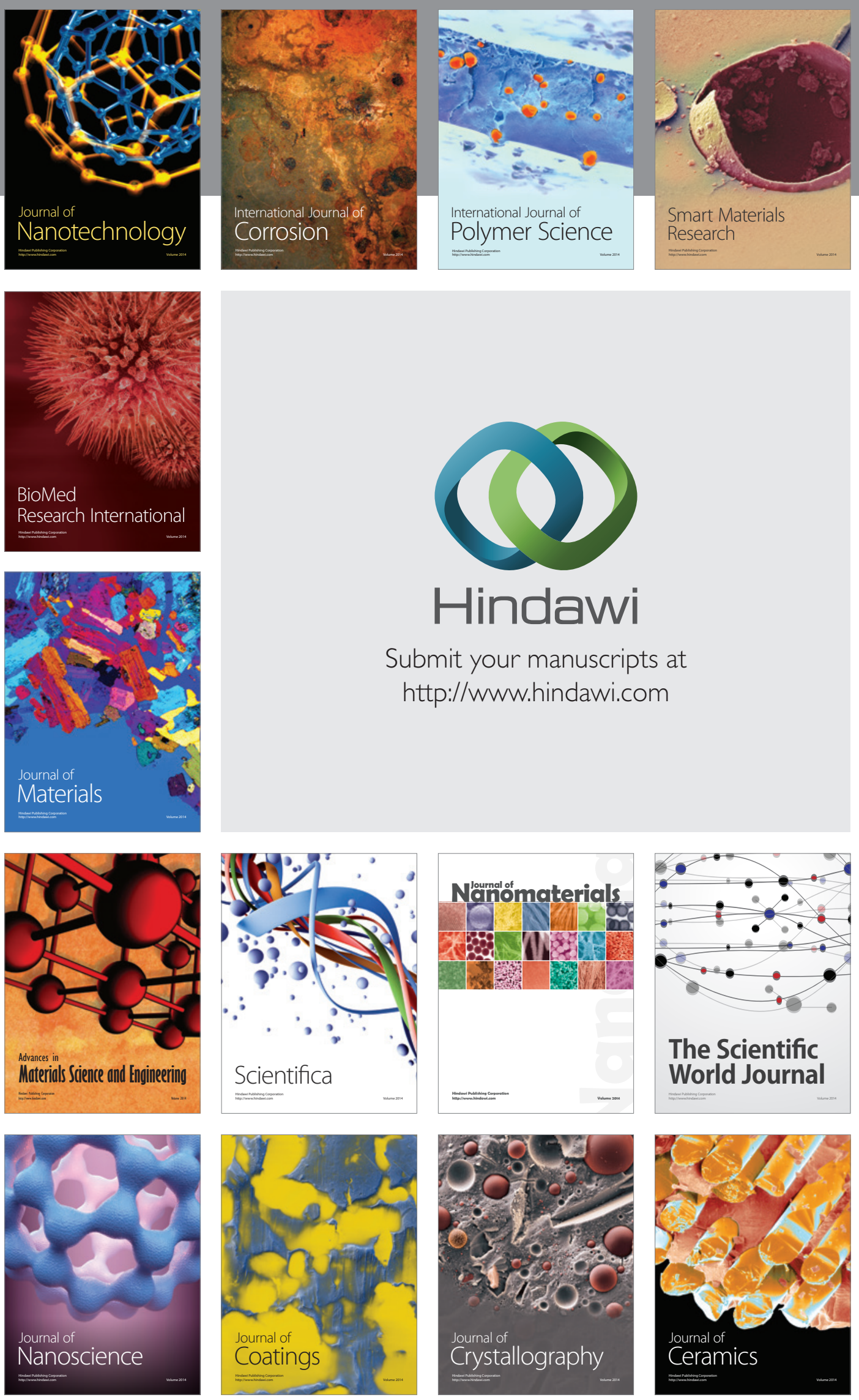

The Scientific World Journal

Submit your manuscripts at

http://www.hindawi.com

\section{World Journal}

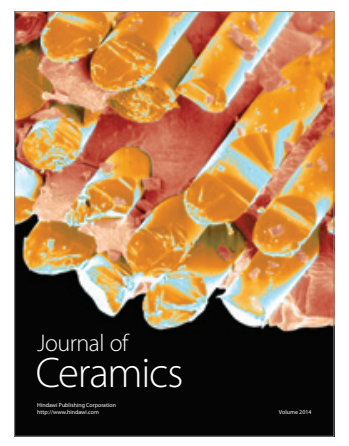

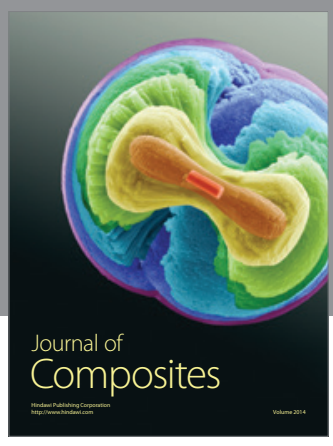
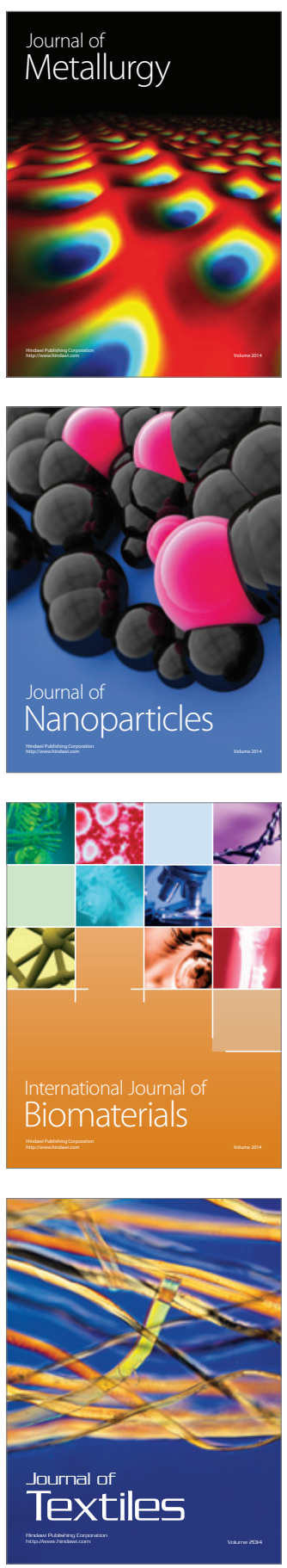